blast-furnaces and coke-ovens exceed the requirements of the blast-furnaces, he regards it as probable that in cases where coke-ovens, blast-furnaces, and steelworks are grouped together sufficient gas will be available to do all the heating at the steelworks without using any raw coal.

(2) Electric Furnaces. - The electro-thermal steel furnace, which up to I9I4 had produced only a very small proportion even of the higher grades of steel, was developed with great rapidity in this country during the war. Germany led in this branch of the industry, and most of the German electric steel was made by refining basic Bessemer steel. Furnaces of 30 tons capacity were used for this purpose. The U.S.A., Italy, and France were all ahead of England in production. To-day the U.S.A. leads, followed by Germany and England. It is stated, however, that the actual number of furnaces and the amount of power used are greater in England than in Germany. By the end of I9I8 no fewer than about i40 furnaces of all types were in use in this country, with a production of I50,000 tons per annum. During the war the output in these furnaces was principally used for making steel for bullet-proof plates, aeroplanes, motor-cars, armour-piercing shells, and steel helmets. Stainless steel is being made in increasing quantities, as are also nickel-chromium and other alloy steels. The significant statement is made that on the Tyne electrothermal steel is being manufactured at a price which can compete with the acid open-hearth steel, since cheap power is available from coke-oven gas. A great advance is foreshadowed in Dr. Stead's reference to the melting of steel in vacuo. Mr. Albert Hiorth, of Christiania, has designed an induction furnace of this type in which the steel is melted and then cooled. Afterwards it is removed and cut up into sections for forgings. It is stated that in this wav steel free from honeycomb and gases is obtained. While it is probable that this process is likely to be, for the present, applied only to the highest qualities of steel, experience mav indicate the desirability of its extension to other varieties later on.

(3) Technical Education.-Dr. Stead finally puts in a powerful plea for the better education of the technical staffs and workmen engaged in the industry. He mentions that many years ago he discussed and formulated a scheme with the late Mr. Andrew Carnegie whereby there was to be established in every industrial centre an institute which could be used as the headquarters of local technical societies, consisting of metallurgists, engineers, electricians, chemists, and others. At this centre proceedings of technical societies and all technical publications were to be assembled. Indexes of subiect-matter would be prepared by a competent staff, and supplied to the general managers of the various industries. After many years' discussion a step in this direction has been taken in the Middlesbrough district. Suitable premises have been obtained, which are being reconstructed to meet local requirements. The sum of about 10,00ol. has been subscribed, and there are promises of annual subscriptions. This, however, is only a beginning, and Dr. Stead, who has nothing if not vision, contemplates an annual contribution from the iron and steel industry for the purpose of making the scheme adequate. He suggests a contribution of $\mathrm{O} . \mathrm{I}$ per cent. on the capital invested, or I per cent. on the actual dividends. Taking the former at, roughly, about $250,000,000 l$., the annual charge would be $250,000 l$. A fund of this magnitude should be sufficient in his opinion to enable technical institutes to be established and maintained in the eight principal iron- and steel-making districts and in NO. 2639 , VOL. IO5]
London, and to carry on their work with a "fair degree of efficiency." It is to be hoped that this suggestion of Dr. Stead's will be vigorously taken up by his council, and a serious attempt made to bring it to fruition.

H. C. H. Carpenter.

\section{The University of London.}

\section{Government Offer of a Site.}

$A \mathrm{~T}$ a meeting of the Senate of the University of A London, held on May I8, the Vice-Chancellor, Dr. Russell Wells, reported that the Chancellor, the Earl of Rosebery, had received from the President of the Board of Education, Mr. H. A. L. Fisher, a communication in the following terms, dated April $7:-$

"The Government have watched with sympathetic interest the efforts which the universities have been making to fit themselves for the task that the period of reconstruction imposes on them, and to take advantage of the opportunities for extending their usefulness which are offered by the steadily growing public recognition of the national importance of a good system of university education. Nowhere are the opportunities more favourable than in London; for as the capital city of the Empire, with the unmatched facilities for manv branches of study and research which its great national collections, hospitals, and public institutions provide, London has always attracted a large number of students, not only from all parts of the United Kingdom. but also from overseas. The war has deepened the general sense of Imperial and international solidarity and has spread more widelv an understanding of the mutual benefits which the different peoples derive from drawing closer the relations between their educational systems; and it is accordingly to be anticipated that in the near future many more university students will be coming to London from our Dominions and Colonies and from foreign countries. This will inevitably place a very serious strain upon the teaching resources of the University of London and will add considerably to the already grave difficulties of organisation by which the University has long been confronted. The Government have, during the past year, sanctioned large increases in the grant to the teaching institutions included in the University of London, as in the grants to the other universities and colleges throughout the country, and no doubt these additional grants should go some way towards enabling the University to meet its increased responsibilities. The mere increase of the grants to individual colleges will not, however, by itself dispose of the special problem which London University has to solve, and the Government are accordinglv prepared to take a further step which thev consider likely to prove of verv material assistance to the University at this critical stage of its development.

"It has seemed to the Government that this is a suitable time at which to make an offer which they have long had under consideration and which they think should help to remove a good many of the administrative difficulties involved in the housing of the University headquarters in the Imperial Institute at South Kensington. The Government are now in a position to acquire a site of about I I $\frac{1}{2}$ acres behind the British Museum, and they offer to devnte it gratis and in perpetuity to the provision of a site for new headquarters of the University and for colleges and institutions connected with it, including King's College, whose premises in the Strand are now 
inadequate for its needs. It would be out of place for me to enlarge on the advantages to be expected from securing the concentration of the headquarters of the University and its two incorporated colleges on a single site, in a quiet residential quarter close to our greatest National Library and Museum, and capable of expansion in the future as the need may arise. The merits of this site, as of other alternative sites which have from time to time been suggested, have, I know, been the subject of much discussion by the friends of university education in London, and I have no doubt that the University is fully apprised of the considerations which need to be weighed. I have no desire to persuade the University against its will. No one recognises more fully than $I$ do the right of universities to control their own destinies and shape their own policies. The responsibility for accepting or declining the Government's offer must rest wholly with the University, which alone is in a position to estimate how far the proposal I communicate to you is likely to advance what it conceives to be its true interests. The view of the Government is, I think, sufficiently indicated by their willingness to provide for the University a site of great value in the heart of London, at a time when there is no temptation to incur expenditure upon any but objects of first-rate urgency and importance.

"It had at one time been my hope that the Government would be able to offer not only the site of which I have spoken, but also the buildings for the new University headquarters : the Government have, however, reluctantly come to the conclusion that, while they are prepared to make such provision as will secure the University from loss in respect of maintenance charges on the new University headquarters, the state of the national finances did not justify their undertaking to provide the cost of the buildings themselves from public funds. They feel that in a matter in which the honour and dignity of the City of London are so nearly concerned, the University can look with confidence to the generosity and public spirit which have always marked the citizens of London: it can do this with the greater assurance that recent years have shown an increasing readiness upon the part of the great business community to respond to appeals for University purposes.

"I am aware that a matter of such importance to the University needs to be fully discussed, and that I cannot fairly expect an immediate answer to the Government's offer. At the same time the University will understand that the Government are naturally anxious to know as soon as possible whether their offer will be accepted or not, since, if it should be declined, they propose to make early use of the site for other purposes. I have, therefore, to ask that the University's answer may not be unduly delayed."

The matter was referred to a special committee for consideration and report as speedily as possible.

\section{Genetic Studies of Drosophila. ${ }^{1}$}

NO single animal has provided such a rich field for discovery in genetics as the little fruit-fly Drosophila (usually known as $D$. ampelophila, but now called $D$. melanogaster), and in this large and handsomely illustrated volume Prof. Morgan and his collaborators bring together the results of some of their

A Contributions to the Genetics of Drosophila melanogaster. I. "The Origin of Gynandromorphs." By T. H. Morgan and C. B. Bridges. II. "The Second Chromosome Group of Mutant Characters." By C. B. Bridges and T. H. Morgan. III. "Inherited Linkage Variations in the Second Chromosome." By A. H. Sturtevant. IV. "A Demonstration of Genes Modifying the Character "Notch," By T. H. Morgan. Pp. v+ $388+12$ plates. Publication No. 278. (Washington: Carnegie Institution of Washington, rgrg.)

NO. 2639 , VOL. IO5] recent work upon it. Of the four parts into which the book is divided, the most interesting is the first, dealing with the gynandromorphic specimens that have appeared in Prof. Morgan's and Dr. Bridges's experiments, and including a most valuable summary and discussion of gynandromorphism in other animals. In Drosophila it appears that about one individual in every 2200 is gynandromorphic, but these gynandromorphs are most varied in their combination of male and female characters. A considerable proportion of those described are bilateral, with male secondary sexcharacters on one side and female on the other; a smaller number are "fore and aft"; while the majority are irregular mosaics, most often with a preponderance of female characters. It is a remarkable fact, however, that in Drosophila, contrary to what is usual in animals of other groups, the two gonads are always of the same sex-doubtless, as the authors point out, in consequence of the very early separation of the primitive germ-cells in the Diptera. As a result of this, it may happen that a fly is externally almost entirely of one sex while containing germ-cells of the other sex, so that Nature here confirms the conclusion reached by Meisenheimer and by Kopec from transplantation experiments, that the sex of the gonad in insects has no influence on the secondary sexual characters. Flies externally chiefly male, but having ovaries instead of testes, court normal females, but attract males.

The authors believe that in all but very exceptional cases gynandromorphs of Drosophila are derived from fertilised eggs which would normally produce females, i.e. from eggs containing two $\mathrm{X}$-chromosomes, and that the male portions arise from cells in which one $\mathrm{X}$-chromosome has been lost through an abnormal mitosis in one of the early segmentation divisions. The evidence for this conclusion is that in almost every instance the sex-linked factors borne (according to the chromosome hypothesis) by the two X-chromosomes introduced from the parents are distributed as might be expected between the male and female portions of the fly. For example, a wild-type female (heterozygous for eosin eye and miniature wing) was crossed with an eosin-miniature male. A gynandromorph among the offspring was female on the left side, with red eyes and long wing, while the right side was male with eosin eye and miniature wing. The explanation offered is that elimination of the maternal X-chromosome on the right side allowed the recessive eosin-miniature characters borne by the remaining X-chromosome to appear. Morgan's earlier hypothesis of the production of gynandromorphs by the entrance of two spermatozoa into the egg, and Boveri's of the division of the egg-nucleus before conjugation with the sperm-nucleus, are excluded by the fact that the non-sex-linked characters borne by the two parents are not divided between the parts showing different sexes. In respect of these characters, all parts of the gynandromorph, whether male or female, bear the dominant characters, whether they are intro. duced by the male or female parent. The analysis of these gynandromorphs thus gives important confirmation to the theory of chromosomes as bearers of hereditary characters. It is remarkable, in this connection, that although elimination of the paternal and maternal X-chromosome is equally common, evidence for the elimination of other chromosomes, which would give mosaics in characters unconnected with sex, is very rarely obtained.

Analysis of the records of gynandromorphs in other groups of animals shows that most are susceptible of the same explanation. In a few cases some other hypothesis, such as that of a binucleate egg, must be invoked. It should be noted that in part $i$. there 